\title{
KAJIAN RESIKO USAHA PENGOLAHAN IKAN TERI DI DESA PAGURAWAN, KECAMATAN MEDANG DERAS, KABUBAPATEN BATUBARA, PROVINSI SUMATERA UTARA
}

\author{
STUDY ON BUSINESS RISK OF THE ANCHOVY'S PROCESSING IN \\ PAGURAWAN VILLAGE, SUB-DISTRICT OF MEDANG DERAS, \\ DISTRICT OF BATUBARA, NORTH SUMATERA PROVINCE
}

\author{
Melva Dumaria Sirait dan Agus Purwoko \\ Jurusan Sosial Ekonomi Pertanian Fakultas Pertanian Universitas Bengkulu
}

\begin{abstract}
This research was done in Desa Pagurawan, Kec. Medang Deras, Kab. Batubara, Provinsi North Utara. The aim of this research were to calculate income of the anchovy's processing business and to analyze it's business risks. All the businessmen of anchovy (32 respondents) were selected by cencus method. The data analysis method used the descriptive analysis and the method of $E-V$ analysis. The research results showed that the income of anchovy processing business was Rp. 5,437,283 per week. The variation coeficient $(\mathrm{CV})$ of the anchovy processing business was 0.04 with the value of the limit lower income (L) was Rp. 5,055,889.11 in a week. If the value of $C V \leq 0.5$ and the value of $L \geq 0$, these mean that the business risk's anchovy processing was lower and the opportunities for getting the profit was high.
\end{abstract}

Keywords: the anchovy's processing business, income, the rsik of business

\section{PENDAHULUAN}

Salah satu komoditi sumberdaya perikanan yang dikenal di Indonesia adalah ikan teri (Stolephorus sp.). Menurut Ningsih (2002), ikan teri adalah salah satu jenis ikan yang paling populer di kalangan penduduk Indonesia. Ikan teri adalah semua jenis ikan dari marga Stolephorus $s p$. dari anak suku Engraulinae. Terdapat beberapa jenis ikan teri, antara lain: ikan teri nasi, ikan teri kacang, dan ikan teri gepeng sebagai produk olahan ikan.

Usaha pengolahan ikan teri banyak dilakukan di Indonesia karena mempunyai prospek untuk dikembangkan yang didukung oleh masih tersedianya sumber daya ikan teri, tingginya tingkat permintaan, serta banyaknya industri rumah tangga pengolah ikan teri. Desa Pagurawan, Kec. 
Medang Deras, Kab. Batubara, Prov. Sumatera Utara merupakan salah satu daerah penghasil ikan olahan, termasuk ikan teri. Ikan teri tersebut merupakan species ikan yang selalu tertangkap hampir sepanjang tahun dengan rata-rata hasil produksi tangkapannya paling tinggi dibandingkan species lainnya, dimana alat tangkap dominan yang digunakan adalah bagan tancap. Produk olahan ikan teri dari dearah ini cukup populer dan telah memasuki pasar berbagai daerah di pulau Sumatera bahkan luar pulau Sumatera.

Kegiatan pengolahan ikan teri di Desa Pagurawan telah cukup lama dilakukan. Para pengusaha ikan teri ini selalu berusaha agar usahanya dapat memberikan pendapatan (keuntungan) yang besar dan mempunyai tingkat resiko yang sekecil-kecilnya. Menurut Antoni dalam Karmini (2005), resiko adalah peluang dimana hasil sesungguhnya bisa berbeda dengan hasil yang diharapkan. Maryam dan Suprapti (2008) menyatakan bahwa sumber resiko yang penting di sektor pertanian, termasuk perikanan laut, adalah fluktuasi hasil produksi dan harga. Istilah resiko banyak digunakan dalam konteks pengambilan keputusan, karena resiko diartikan sebagai peluang akan terjadinya suatu kejadian buruk akibat suatu tindakan. Makin tinggi tingkat ketidakpastian suatu kejadian, makin tinggi pula resiko yang disebabkan oleh pengambilan keputusan itu. Dengan demikian, identifikasi sumber resiko sangat penting dalam proses pengambilan keputusan.

Resiko dapat juga ditemukan pada usaha pengolahan ikan teri yang dilakukan di Desa Pagurawan.. Tingkat resiko yang dialami pengolah ikan teri yaitu rentannya kerusakan (pembusukan) terhadap ikan teri yang baru ditangkap sebagai akibat pengaruh fisik, kimiawi dan mikrobiologi. Apabila ikan tidak segera diolah maka akan mengakibatkan kerugian terhadap usaha ini, dimana bentuk pengolahan yang dilakukan adalah pengasinan dan pengeringan. Resiko lainnya adalah waktu penyimpanan ikan teri yang sudah kering. Ikan teri tidak boleh disimpan terlalu lama karena akan berpengaruh pada kualitasnya, yakni akan menguning apabila disimpan terlalu lama. Lama penyimpanan maksimal ikan teri hanya sekitar satu bulan saja. Resiko usaha pengolahan ikan teri di Desa Pagurawan dalam penelitian ini berhubungan dengan pendapatan pengusaha ikan teri setiap minggunya, dimana data yang digunakan adalah data selama tiga minggu.

Berangkat dari diskusi di atas, tujuan dari penelitian ini adalah menghitung besarnya pendapatan pengusaha ikan teri di Desa Pagurawan dan menganalisis besarnya resiko usaha yang harus ditanggung oleh pengusaha ikan teri.

\section{METODE PENELITIAN}

Penelitian ini dilaksanakan di Desa Pagurawan, Kec. Medang Deras, Kab. Batubara, Prov. Sumatera Utara karena daerah ini merupakan salah satu sentra pengolahan ikan teri. Penentuan responden dalam penelitian ini dilakukan 
dengan cara sensus pada semua pengolah ikan teri, yakni 32 orang. Seluruh responden merupakan pengusaha ikan teri yang mengolah ikan teri di daratan bukan melakukan pengolahan di kapal ketika sedang berlayar.

Data primer dikumpulkan berdasarkan hasil wawancara langsung dengan pengolah ikan teri dengan menggunakan alat bantu berupa kuesioner. Data ini meliputi data biaya produksi, produksi yang dihasilkan, penerimaan selama tiga minggu. Data sekunder adalah data yang diperoleh berdasarkan literatur atau pustaka yang berkaitan dengan penelitian ini.

\section{Analisa Pendapatan}

Untuk analisis pendapatan usaha pengolahan ikan teri adalah dengan menghitung selisih penerimaan dengan pengeluaran, sedangkan bahasannya digunakan analisis deskriptif (Meleong, 2004 dan Sukandarrumidi, 2004). Secara matematis, pendapatan usaha dapat dirumuskan sebagai berikut:

$$
\begin{aligned}
& \mathrm{Pd}=\mathrm{TR}-\mathrm{TC} \\
& \mathrm{TR}=\sum \mathrm{Yi} \times \mathrm{Pyi} \\
& \mathrm{TC}=\mathrm{TFC}+\mathrm{TVC}
\end{aligned}
$$

dimana $\mathrm{Pd}=$ Pendapatan, $\mathrm{TR}=$ Total Revenue $($ Total Penerimaan), $\mathrm{TC}=$ Total Cost (Total Biaya), yang terdiri dari Total Biaya Tetap (TFC) dan Total Biaya Variabel (TVC).

\section{Analisa Resiko}

Besarnya resiko usaha pengolahan ikan teri dianalisa dengan menggunakan metode hasil yang diharapkan (E) dan besarnya resiko (V) yang diadopsi dari Hernanto (1989) dan Kadarsan (1992) dengan rumus sebagai berikut:

\section{Hasil yang diharapkan (E)}

Hasil yang diharapkan ini dihitung dari rata-rata keuntungan pada setiap pengusaha ikan teri dengan rumus:

$$
E=\frac{\sum_{i=1}^{n} E i}{n}
$$

dimana $\mathrm{E}=$ Pendapatan rata-rata hasil yang diharapkan $(\mathrm{Rp} / \mathrm{minggu}), \mathrm{Ei}=$ Pendapatan satu kali periode pengamatan ( $\mathrm{Rp} / \mathrm{minggu}), \mathrm{n}=$ Jumlah periode pengamatan (dalam penelitian ini ada 3 periode).

\section{Resiko usaha $\left(V^{2}\right)$}

Untuk mengukur resiko usaha, secara statistik sering dipakai ukuran ragam (variance) atau simpangan baku. Kedua cara ini menjelaskan resiko dalam 
arti kemungkinan berserakannya pengamatan sebenarnya di sekitar nilai ratarata yang diharapkan, dengan rumus sebagai berikut:

$$
V^{2}=\frac{\sum_{i=1}^{n}(E i-E) 2}{(n-1)}
$$

Simpangan baku merupakan akar dari ragam dengan rumus:

$$
\mathrm{V}=\sqrt{V^{2}}
$$

dimana $\mathrm{V}^{2}=$ Ragam (variance), $\mathrm{V}=$ Simpangan baku pendapatan $(\mathrm{Rp} / \mathrm{minggu}), \mathrm{E}=$ Pendapatan rata-rata hasil yang diharapkan $(\mathrm{Rp} / \mathrm{minggu})$, $\mathrm{Ei}=$ Pendapatan satu kali periode pengamatan $(\mathrm{Rp} / \mathrm{minggu}), \mathrm{n}=$ Jumlah periode pengamatan (dalam penelitian ini ada 3 periode).

\section{Hubungan Resiko dengan Pendapatan}

Dalam proses produksi, produsen (pengolah ikan teri) harus memperhitungkan berapa resiko yang akan ditanggung dibandingkan dengan pendapatan yang akan diperoleh. Hubungan tersebut diukur dengan menggunakan koefisien variasi (CV) dengan batas bawah pendapatan (L). Koefisien variasi merupakan perbandingan antara resiko yang harus ditanggung dengan keuntungan yang akan diperoleh sebagai hasil dari sejumlah modal yang diinvestasikan dalam proses produksi. Semakin besar nilai koefisien variasi ini menunjukkan bahwa resiko yang ditanggung semakin besar dibandingkan dengan keuntungan. Rumus yang digunakan yaitu:

$$
\mathrm{CV}=\frac{V}{E}
$$

dimana CV adalah Koefisien variasi, $\mathrm{V}$ adalah Simpangan baku (Rp/minggu), $\mathrm{E}$ adalah Pendapatan rata-rata hasil yang diharapkan (Rp/minggu).

Untuk mengukur batas bawah hasil pendapatan, rumus berikut yang digunakan:

$$
\mathrm{L}=\mathrm{E}-2 \mathrm{~V}
$$

dimana $\mathrm{L}$ adalah Batas bawah hasil pendapatan (Rp/minggu), $\mathrm{E}$ adalah Pendapatan rata-rata hasil yang diharapkan ( $\mathrm{Rp} / \mathrm{minggu}), \mathrm{V}$ adalah Simpangan baku (Rp/minggu).

Dari rumus-rumus di atas dapat diperoleh hubungan antara batas bawah hasil keuntungan dengan nilai koefisien variasi. Apabila nilai $\mathrm{CV}>0,5$ maka nilai $\mathrm{L}<0$ yang berarti bahwa pada setiap proses produksi ada peluang pengolah ikan teri tersebut mendapat kerugian. Sebaliknya, apabila nilai CV $\leq$ 0,5 maka nilai $\mathrm{L} \geq 0$ yang berarti pengolah ikan teri tersebut akan selalu mendapatkan keuntungan. 


\section{HASIL DAN PEMBAHASAN}

\section{Pola Usaha Pengolahan Ikan Teri}

Pola usaha pengolahan ikan teri di Desa Pagurawan merupakan kondisi usaha pengolahan ikan teri secara menyeluruh yang dikaitkan dengan pemilihan dan pengadaan bahan baku beserta harganya, proses produksi, pengadaan modal dan biaya-biaya yang dikeluarkan, produksi ikan teri beserta harganya, dan wilayah pemasarannya.

Bahan baku ikan teri diperoleh dari nelayan dan/atau pedagang pengumpul ikan segar. Banyak sedikitnya bahan baku yang akan diolah bergantung pada musim. Musim ikan teri terjadi pada musim kemarau, sedangkan jika musim penghujan ikan teri hasil tangkapan nelayan lebih sedikit jika dibandingkan musim kemarau. Apabila bahan baku banyak maka produksi ikan teri akan tinggi, sebaliknya apabila bahan baku susah diperoleh maka produksi ikan teri menjadi rendah. Dengan demikian, ketersediaan jumlah bahan baku mempengaruhi harganya. Harga bahan baku sangat stabil selama 3 minggu pengamatan, dimana selisih harga tertinggi dengan harga terendah sebesar Rp. 1.000,00/ kg untuk setiap jenis bahan baku pengolahan ikan teri, seperti disajikan pada Tabel 1.

Tabel 1. Rata-rata harga beli bahan baku pada usaha pengolahan ikan teri (dalam Rp/kg).

\begin{tabular}{clccc}
\hline No. & Jenis Bahan Baku & $\begin{array}{c}\text { Harga } \\
\text { Terendah }\end{array}$ & $\begin{array}{c}\text { Harga } \\
\text { Tertinggi }\end{array}$ & $\begin{array}{c}\text { Rerata per } \\
\text { Minggu }\end{array}$ \\
\hline 1 & Ikan teri nasi & 30.000 & 31.000 & 30.500 \\
2 & Ikan teri gepeng & 24.000 & 25.000 & 24.500 \\
3 & Ikan teri kacang & 12.000 & 13.000 & 12.500 \\
4 & Cumi kecil & 8.000 & 9.000 & 8.500 \\
\hline
\end{tabular}

Sumber: Analisis data primer, 2012

Proses pengolahan ikan teri yang dilakukan oleh pengusaha di Desa Pagurawan diperlihatkan pada Gambar 1. Hasil penelitian menunjukkan bahwa para pengusaha ikan teri rata-rata memiliki modal sendiri dalam menjalankan usahanya. Modal yang dimiliki digunakan untuk pengadaan bahan baku dan biaya-biaya produksi yang harus dikeluarkan pengolah ikan teri. Pola biaya yang dikaji adalah biaya produksi yang terdiri dari biaya tetap dan biaya variabel. 


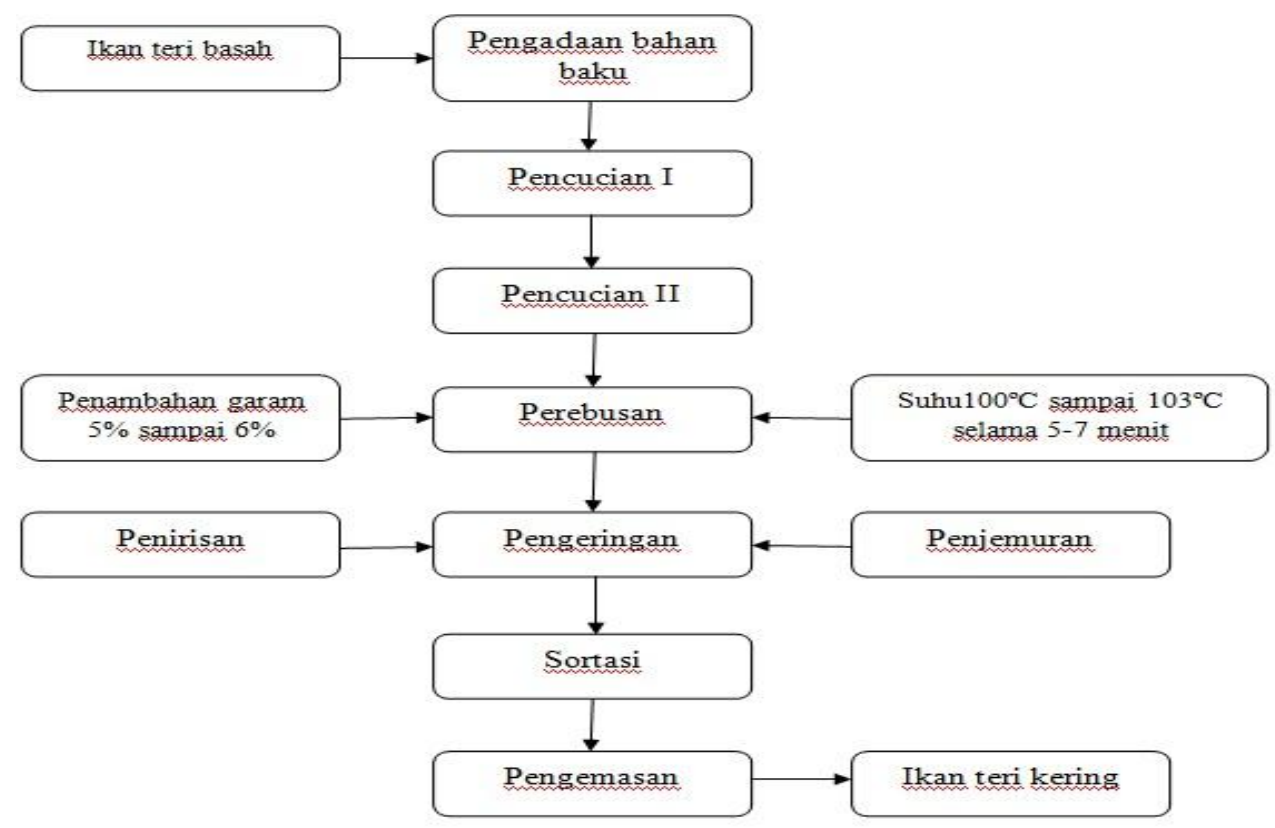

Gambar 1. Diagram alir proses produksi ikan teri (Stolephorus sp.)

Tabel 2. Rata-rata biaya produksi pada usaha pengolahan ikan teri (dalam $\mathrm{Rp})$.

\begin{tabular}{|c|c|c|c|c|c|}
\hline No. & Uraian Biaya Produksi & Minggu I & Minggu II & Minggu III & $\begin{array}{l}\text { Rerata per } \\
\text { Minggu }\end{array}$ \\
\hline \multirow[t]{2}{*}{ A. } & Biaya Tetap & & & & \\
\hline & Penyusutan peralatan & $51.160,84$ & $52.365,47$ & $52.425,46$ & $51.983,92$ \\
\hline \multirow[t]{8}{*}{ B. } & Biaya Variabel: & & & & \\
\hline & 1. Bahan baku & $7.557 .876,0$ & $7.922 .187,5$ & $7.751 .562,5$ & $7.743 .875,0$ \\
\hline & 2. TK dlmkeluarga & $10.273,83$ & $10.546,88$ & $10.546,88$ & $10.455,86$ \\
\hline & 3. TKluar keluarga & $288.780,00$ & $295.898,43$ & $295.898,44$ & $293.525,60$ \\
\hline & 4. Listrik & $28.108,37$ & $56.562,50$ & $56.562,50$ & $47.077,79$ \\
\hline & 5. Bahan bakar & $28.108,37$ & $28.796,88$ & $28.796,87$ & $28.567,37$ \\
\hline & 6. Bahan penolong & $551.023,50$ & $564.678,12$ & $564.678,13$ & $560.126,60$ \\
\hline & 7. Bahan baku rusak & $688.906,30$ & $688.906,25$ & $688.906,25$ & $688.906,30$ \\
\hline C. & Total Biaya & $9.204 .237,0$ & $9.619 .942,03$ & $9.4493 .77,03$ & $9.424 .519,00$ \\
\hline
\end{tabular}

Sumber: Analisis data primer, 2012

Hampir seluruh biaya yang dikeluarkan oleh pengusaha ikan teri merupakan biaya variabel. Biaya bahan baku merupakan biaya paling besar $(82,17 \%)$ dari seluruh biaya yang harus dikeluarkan, kemudian disusul biaya bahan baku yang rusak sebesar 7,31\% dan biaya bahan penolong sebesar 5,94\%. Biaya bahan penolong terdiri atas: garam, es batu, sak semen, dan kantong 
plasik. Hal ini mengindikasikan bahwa usaha pengolahan ikan teri sangat bergantung pada ketersediaan bahan bakunya.

Hasil dari proses pengolahan ikan teri di daerah penelitian terdiri atas: ikan teri nasi (teri kasar, teri sedang, dan teri halus), ikan teri gepeng, ikan teri kasar, dan cumi kecil sebagai produk sampingan. Tabel 3 memperlihatkan bahwa ikan teri nasi merupakan produk utama yakni 170,52 $\mathrm{kg}$ atau $44,4 \%$ dari total produk yang diolah setiap minggunya, sedangkan produk cumi kecil hanya $1,4 \%$ saja.

Tabel 3. Rata-rata produksi pada usaha pengolahan ikan teri (dalam kg).

\begin{tabular}{clcccc}
\hline \multirow{2}{*}{ No. } & \multirow{2}{*}{ Jumlah Produksi } & \multicolumn{3}{c}{ Minggu } & \multirow{2}{*}{ Rerata } \\
\cline { 2 - 4 } & I & II & III & \\
\hline 1 & Ikan teri nasi & 170,00 & 174,06 & 167,50 & 170,52 \\
2 & Ikan teri gepeng & 60,00 & 96,81 & 85,84 & 80,89 \\
3 & Ikan teri kacang & 98,44 & 157,03 & 126,69 & 127,39 \\
4 & Cumi kecil & 0,00 & 8,53 & 8,19 & 5,57 \\
\hline
\end{tabular}

Sumber: Analisis data primer 2012

Tabel 4. Rata-rata harga jual pada usaha pengolahan ikan teri (dalam Rp/kg).

\begin{tabular}{clccc}
\hline No. & \multicolumn{1}{c}{ Jenis Produksi } & $\begin{array}{c}\text { Harga } \\
\text { Terendah }\end{array}$ & $\begin{array}{c}\text { Harga } \\
\text { Tertinggi }\end{array}$ & $\begin{array}{c}\text { Rerata per } \\
\text { Minggu }\end{array}$ \\
\hline 1 & Ikan teri nasi & & & \\
& Teri nasi kasar & 76.000 & 77.000 & 76.500 \\
& Teri nasi sedang & 68.000 & 69.000 & 68.500 \\
& Teri nasi halus & 62.000 & 63.000 & 62.500 \\
2 & Ikan teri gepeng & 38.000 & 39.000 & 38.500 \\
3 & Ikan teri kacang & 22.000 & 23.000 & 22.500 \\
4 & Cumi kecil & 19.000 & 20.000 & 19.500 \\
\hline
\end{tabular}

Sumber: Analisis data prime,r 2012

Sama halnya dengan harga bahan baku, selama 3 minggu pengamatan harga produk olahan ikan teri sangat stabil, dimana selisih harga tertinggi dengan harga terendah sebesar Rp. 1.000,00/ $\mathrm{kg}$ untuk setiap jenis jenis ikan teri dan cumi kecil sebagai produk sampingan, seperti ditampilkan pada Tabel 4 . Hal ini memberikan indikasi bahwa resiko harga pada usaha pengolahan ikan teri di Pagurawan hampir tidak terjadi selama penelitian.

Pola pemasaran pada usaha pengolahan ikan teri mencakup wilayah pemasaran dan harga. Harga terdiri dari harga beli bahan baku dan harga jual hasil produksi. Wilayah pemasaran Ikan teri yang dihasilkaa Desa Pagurawan, antara lain: Pematang Siantar, Medan, Tebing Tinggi, Pekanbaru dan Dumai. Adapun harga jual hasil produksi tergantung dengan harga pasaran yang berlaku. 


\section{Analisis Pendapatan dan Resiko Usaha Pengolahan Ikan Teri}

Penerimaan usaha pengolahan ikan teri merupakan hasil perkalian produksi dengan harga produk, untuk setiap jenis produk pengolahan ikan teri. Adapun pendapatan yang diperoleh pengusaha ikan teri adalah selisih antara penerimaan dengan biaya produksi yang dikeluarkan pengusaha setiap minggunya.

Tabel 5. Rata-rata penerimaan, biaya produksi, dan pendapatan pada usaha pengolahan ikan teri (dalam Rp/minggu).

\begin{tabular}{clrrr}
\hline No. & \multicolumn{1}{c}{ Jenis Produksi } & Penerimaan & Biaya Produksi & \multicolumn{1}{c}{ Pendapatan } \\
\hline 1 & Ikan teri nasi & $11.747 .135,42$ & $6.757 .460,80$ & $4.989 .674,62$ \\
2 & Ikan teri gepeng & $1.784 .687,50$ & $1.578 .939,30$ & $2.057 .48,20$ \\
3 & Ikan teri kacang & $1.227 .968,87$ & $1.0295 .66,09$ & $198.402,77$ \\
4 & Cumi kecil & $111.041,67$ & $60.629,97$ & $50.411,70$ \\
\hline & Jumlah & $14.870 .833,45$ & $9.426 .596,16$ & $5.444 .237,29$ \\
\hline
\end{tabular}

Sumber: Analisis data primer, 2012

Tabel 5 menunjukkan bahwa rata-rata pendapatan setiap minggu yang diperoleh pengusaha berasal dari ikan teri nasi yakni Rp. 4.989,675,00 atau $91,65 \%$ dari total pendapatan. Adapun cumi kecil sebagai hasil sampingan hanya memperikan kontribusi sebesar $0,93 \%$ dari total pendapatan. Sementara itu, Tabel 6 menyajikan data pendapatan selama 3 periode pengamatan (3 minggu) untuk keperluan analisis resiko usaha pengolahan ikan teri.

Para pengusaha (pengolah) ikan teri selalu dihadapkan pada peristiwaperistiwa yang menyangkut ketidakpastian yakni resiko yang harus ditanggung dengan keuntungan yang diperolehnya. Resiko yang ditanggung terdiri atas resiko produksi dan resiko harga. Resiko produksi disebabkan oleh ketidaktentuan iklim yang berada di laur kontrol pengusaha. Resiko harga dikarenakan oleh harga input dan harga output yang ditentukan oleh kekuatan permintaan dan penawaran pasar. Analisis resiko sangat berguna bagi pengusaha ikan teri dalam mengambil keputusan untuk langkah selanjutnya dan kekhawatiran akan adanya kemungkinan merugi menjadi berkurang.

Tabel 6. Rata-rata pendapatan pada usaha pengolahan ikan teri (dalam $\mathrm{Rp} /$ minggu).

\begin{tabular}{rlrrrr}
\hline No & Jenis Produksi & Minggu I & Minggu II & Minggu III & \multicolumn{1}{c}{$\begin{array}{c}\text { Rerata per } \\
\text { Minggu }\end{array}$} \\
\hline 1 & Ikan teri nasi & $4.942 .602,17$ & $5.128 .078,97$ & $4.898 .342,72$ & $4.989 .674,62$ \\
2 & Ikan teri gepeng & $159.391,91$ & $216.582,94$ & $241.269,76$ & 205748,20 \\
3 & Ikan teri kacang & $159.705,20$ & $209.237,05$ & $226.266,07$ & $198.402,77$ \\
4 & Cumi kecil & 0,00 & $86.255,61$ & $64.979,48$ & $50.411,70$ \\
\hline & Jumlah & $5.261 .699,28$ & $5.640 .154,57$ & $5.430 .858,03$ & $5.444 .237,29$ \\
\hline
\end{tabular}

Sumber: Analisis data primer 2012

194 | Melva Dumaria Sirait dan Agus Purwoko. Kajian Resiko Usaha ... 
Tabel 7. Analisis resiko pendapatan pada usaha pengolahan ikan teri

\begin{tabular}{ll}
\hline \multicolumn{1}{c}{ Uraian } & \multicolumn{1}{c}{ Nilai } \\
\hline Mean (E) & Rp. 5.444.237,29 \\
Simpangan baku (V) & Rp. 190.697,32 \\
Koefisien Variasi (CV) & 0,04 \\
Batas bawah pendapatan (L) & Rp. 5.055.889,11 \\
\hline
\end{tabular}

Sumber: Analisis data primer, 2012

Berdasarkan tabel di atas diketahui bahwa rata-rata pendapatan yang diharapkan (E) oleh pengusaha ikan teri sebesar Rp. 5.444.237,00 setiap minggunya. Varian $\left(\mathrm{V}^{2}\right)$ adalah ukuran yang menunjukkan tingkat keragaman pendapatan selama periode pengamatan, sedangkan simpangan baku (V) adalah rentang selisih pendapatan dari periode pengamatan pertama ke periodeperiode berikutnya. Semakin tinggi nilai simpangan baku berarti semakin besar ketidakpastian (resiko) yang harus ditanggung oleh pengusaha teri. Kemungkinan resiko yang harus ditanggung pengusaha teri sebesar Rp. 190.697,00/minggu.

Besarnya resiko terendah dapat diketahui dengan melihat hubungan $\mathrm{E}$ dan $\mathrm{V}$ melalui pengukuran koefisien variasi $(\mathrm{CV})$ dan batas bawah pendapatan yang diperoleh (L). Analisis data menghasilkan nilai CV sebesar 0,04, sedangkan nilai L sebesar Rp. 5.055.890,00/minggu. Dikarenakan nilai CV $\leq 0,5$ dan nilai $L \geq 0$, maka pengusaha ikan teri di Pagurawan mempunyai peluang memperoleh keuntungan untuk setiap proses pengolahan ikan teri.

\section{SIMPULAN DAN SARAN}

\section{Simpulan}

1. Pendapatan yang diperoleh pengusaha ikan teri sebesar Rp. $5.444 .237,00 /$ minggu.

2. Nilai koefisien variasi $(\mathrm{CV})$ sebesar 0,04 dengan nilai batas bawah pendapatan (L) sebesar Rp.5.055.890,00/minggu, sehingga pengusaha ikan teri selalu berpeluang memperoleh keuntungan dalam setiap proses pengolahan ikan teri.

\section{Saran}

Untuk mengatasi gangguan cuaca pada musim penghujan, maka sebaiknya pengusaha ikan teri menggunakan drying machine pada proses pengeringan. Hal ini ditujukan untuk mempertahan bahkan meningkatkan kuantitas dan kualitas ikan teri nasi yang dihasilkan. 


\section{DAFTAR PUSTAKA}

Hernanto, F. 1989. Ilmu Usahatani. Penebar Swadaya, Jakarta.

Kadarsan, H. W. 1992. Keuangan Pertanian dan Pembiayaan Perusahaan Agribisnis. Gramedia Pustaka Utama, Jakarta

Karmini. 2005. Resiko Perubahan Harga dalam Pemasaran Beras Lokaldan Impr di Indonesia. Jurnal Ekonomi Pertanian 2(2);34-40.

Maryam, S dan Suprapti. 2008. Studi Banding Resiko Ekonomi Usaha Tani Pepaya Varietas Thailand dan Hawaii. Jurnal Ekonomi Pertanian 5(1):815.

Meleong, L.J. 2004. Metodologi Penelitian Kualitatif. Edisi 1. Cetakan ke-18. PT Remaja Rosdakarya, Bandung

Ningsih, K. 2002. Analisis Keunggulan Komparatif dan Kompetitif Usaha Pengolahan Ikan Teri Nasi Kering (Stollephorus commersonii Lac.) Studi Kasus di PT Madura Prima Interna, Desa Kapedi, Kecamatan Bluto, Kabupaten Sumenep, Madura. Skripsi. Fakultas Pertanian, Institut Pertanian Bogor, Bogor

Sukandarrumidi. 2004. Metode Penelitian: Petunjuk Praktis untuk Peneliti Pemula. Cet. Ke-2. Gadjah Mada University Press, Yogyakarta. 